\title{
Toothlessness - A moral crisis of unprecedented proportions.
}

SADJ June 2018, Vol 73 no 5 p368 - p371

PD Motloba', LN Makwakwa. ${ }^{2}$

\section{CASE PRESENTATION}

The cases presented highlight the typical experiences of patients who have lost their teeth, and are enduring the consequences of toothlessness and immense negative impact on the quality of life. Many patients attending public dental services endure a variety of complications resulting from multiple extractions leading to toothlessness.

Case 1: A dentectomy was performed on a teenage girl, as no other treatment was deemed clinically appropriate or suitable to manage her aggressive localised juvenile periodontitis. Bereft of her teeth, she shied away from her friends and started missing social engagements. Virtually ostracized, she withdrew from the social activities typical of a teenager due to a sense of inadequacy and embarrassment.

Case 2: A nursing sister presented at a dental surgery after her partial dentures broke while she was having lunch. She subsequently missed two days of work while waiting to have the prostheses repaired. The ordeal affected her ability to enjoy a variety of food. Her ability and desire to communicate and engage with family and in social activities were also adversely affected.

\section{BACKGROUND}

In South Africa, as in many developing countries, extractions are the mainstay of dental treatment., ${ }^{1,2}$ This practice has been medically socialised as an acceptable and inconsequential alternative care by patients and dental professionals. Data from the South African National Oral Health Directorate on public oral health service indicate that at least five of seven patients will undergo dental extraction as part of their clinical management.

1. Prof. Pagollang D Motloba: BDS (Medunsa), MPH (Epidemiology) (Tulane), M Dent (Comm Dent) (Medunsa), MBL (Unisa). Chief Specialist, Head, Department of Community Dentistry, School of Ora Health Sciences - Sefako Makgatho Health Science University (SMU).

2. Dr Khyani Makwakwa: BDT, BDS (Medunsa) Postgraduate Dip in Clinical Dentistry (UWC), MPH (UL). Registrar, Community Dentistry, School of Oral Health Sciences - Sefako Makgatho Health Science University (SMU).

\section{Corresponding author}

Prof. Pagollang D Motloba:

HOD, Department of Community Dentistry, School of Oral Health

Sciences, Sefako Makgatho Health Science University (SMU), South

Africa. Tel: +27 12 521- 4848/5767. Email: pagollang.motloba@smu.ac.za
This translates into an average of 14 extractions for every restored tooth in 'resourced' facilities. In some regions the ratio of extractions to restorations is as high as $44: 1$, and in the worst instances, no restorations are performed at all, but only dental extractions.

It is quite plausible that this trend will continue unabated, unless (i) a radical paradigm shift occurs in the delivery of oral health services; (ii) the perceptions and attitudes of patients regarding dental care are drastically altered and (iii) clinicians focus on oral health promotion, prevention and restorative care.

The genesis of this unprecedented extraction epidemic is complex and controversial. In South Africa the phenomenon can be traced back to historical legacies of the segregated health care system in the pre-democratic era (long before 1994). ${ }^{3,4}$ Unfortunately the effects of the unequal health system remain deeply entrenched. Structurally and operationally, Oral Health Services remain relatively underfunded and less prioritised when compared with other health programs. ${ }^{5}$ Consequently, the under-resourced Oral Health Services are restricted to offering limited treatment options for attending patients. It is of course conceivable that clinicians could be partly responsible for the spate of extractions, electing the convenience, rather than the necessity, of removal in preference to the time consuming effort of restorations. This situation is likely to continue or even worsen, because of patient and clinician factors that perpetuate the demand for, and the provision of, dental extractions.

Under these circumstances, we ask if it is indeed moral or just for dental professionals, especially those in the public sectors, to continue a practice that renders populations edentulous at an unprecedented rate? Phrased differently, is it moral for the oral health system to provide dental extractions as the predominant form of dental care? Is the oral health system so designed (structurally and otherwise), that dental extractions are offered, almost exclusively, is that just or fair, especially to the indigent patients who rely solely on the public oral health system?

\section{CONTEXTUALISING TOOTHLESSNESS AS} A CLINICAL CONSEQUENCE

Despite being the most common dental procedure, extractions are physically and psychologically traumatic to patients. ${ }^{6}$ Dental extraction could be indicative of the end 
of clinical possibilities in managing diseases or conditions related to the teeth. Ceteris paribus, it is mandatory that the clinician explore alternatives to save the tooth instead of recommending amputation. This clinical endpoint has in some instances become intuitive structurally and socially accepted dental service option, especially for the indigent and vulnerable patients. Dental extractions are the standard of care available in oral health services in most developing countries. ${ }^{1}$ Whether by necessity or convenience, the scourge of tooth amputation continue in these settings. Dental professionals have become desensitised to the impact of extractions; and patients have become socialised to accept or demand extractions even when alternatives exist. To that extent, the oral health service has to confront and deal with the eventual clinical sequelae of dental extractions, whether leading to partial or complete toothlessness.

Edentulism is a form of impairment which result in disability and functional limitation, since affected patients are unable to perform normal functions such as biting, chewing and swallowing and that affects their food choices. ${ }^{7}$ Overwhelming evidence points to the devastating impact of toothlessness on the patient's psychological and general wellbeing and overall quality of life. ${ }^{8,9}$ The extent of impairment, disability and handicap, and the effect on quality of life is influenced by sex, gender social and cultural factors, among others. 8,10

The aim of this paper is to evaluate the morality of the sustained levels of dental extractions as presently undertaken in the Public Oral Health Services. Normative analysis of this moral question is premised on philosophical theories as explicated by Daniels, Kant, Bentham and Mill. ${ }^{17,23}$

\section{BRIEF OVERVIEW OF MORAL THEORIES}

The morality of an act is determined by the extent to which it complies with common or particular moral norms or principles. In this paper, we evaluate how dental extractions and eventual toothlessness may not be morally just, nor beneficial or harmless to patients.

According to egalitarian moral theories, all mankind share common human characteristics, are created equally, and have equal moral status. ${ }^{11}$ As a consequence, all persons are owed rights and obligations given their moral status. The existence of any inequalities in a society is therefore an indictment on this principle of equal distribution of benefits and burdens, and is a violation of the equality of rights and obligations.

Rawls' interpretation of liberty and justice provides an eloquent discussion of rights and obligations owed to moral being. ${ }^{11-14}$ His assertion is based on the assumption of "original position" in which all persons are subjected to a veil of ignorance. From that starting point, it may be proposed that: (i) all persons should achieve similar maximum levels of liberties and basic rights (Liberty Principle); (ii) offices and positions be open to all in pursuit of fair equality of opportunity (Opportunity Principle) and (iii) inequality is only permissible if it benefits all, especially the least advantaged (Difference Principle). ${ }^{11-14}$ This Rawlsian idealisation of justice sought to redress the effects of societal inequality. However, Rawls observed that the "natural lottery" or immutable disposition acquired at birth, somewhat limited individual opportunities to attain life goals. Similarly, "social lottery" or structural and socially designed barriers, denied individuals fair and equal opportunities..$^{15,16}$ Hence the focus of Rawls' theory was on the distribution of income, wealth, choice and did not specifically address health. ${ }^{14}$ The application of his theory to health issues was further developed by Norman Daniels to give effect to consideration of justice in the distribution of health as a social good. ${ }^{17}$

Daniels' central premise is that justice will be achieved when there is equal and fair opportunity "for all to realise their maximum species- typical level of functioning". Daniels further argued that health care needs are special and morally important due to their contribution to the achievement of normal functioning and the protection of the equality of opportunity. Consequently, any deficiency in health would minimize the attainment and maintenance of normal function, and would limit the range of opportunities, predisposing individuals to pain, suffering and unhappiness. ${ }^{18,19}$ Therefore, all health activities are just to the extent they ensure fair equal opportunity necessary for the individual to construct and achieve life plans and objectives. The range of opportunities due to individuals or societies will vary according to the level or stage of development, cultural preferences and other material factors. Despite these differences, just societies ought to provide a minimum standard of care for all, which would enable individuals to attain acceptable levels of function.

According to Daniels, prioritization of health needs and the implementation of appropriate programs will depend on the relative importance attached to a particular health need and its expected impact on achievement of life plans. This means that resources will be allocated to a basket of health services depending on their impact on function and the opportunities they provide to individuals. In the case of dental services and in particular the sole provision of extractions, the question must be raised as to whether oral health services are adequately prioritised and funded to enable achievement of functioning and opportunities? In other words, are dental extractions in public oral health services a reasonable treatment that contributes to the individual's ability to achieve and to construct one's life plans? If not so, why do we continue to perform dental extractions?

Daniels regards health as a special "good", hence the moral requisite to make access to health universal, and not dependent one's financial resources. ${ }^{18,19}$ Yet given the limited nature of health resources, some form of rationing is necessary, as long as it is just and fair. Daniels suggests that transparent judgment be made according to needs, in order to determine which healthcare resources are allocated and to whom. This means that limits have to be set on what services can be provided universally, given that the resources are finite and are sometimes indivisible, rendering it not possible to permit "equal" allocation. According to Daniels a just health system should defend Rawls' idealization of health, by assuring that speciesspecific opportunities are realised. With regards to oral health, is it morally just for dental extractions to be the primary and most accessible service in the public service? What other treatment modalities should constitute a basic 
dental care package that would ensure realization and protection of normal functioning?

Bentham and Mill teleological philosophical ethics emphasise that the consequences, or the ends or the utility of an action determines its moral value. Therefore, an action that produces greatest happiness for the greatest number of persons is consequently moral. ${ }^{20,21}$ Dental extractions result in short term relief of pain and suffering for patients, which, according to consequentialism or utilitarianism, makes the provision of this form of care morally just. Patients receiving dental extractions get relief from pain and discomfort, which maximises happiness. However, this short term gain is offset by huge costs of toothlessness, as patients would require rehabilitative services which are financially, socially, psychologically costly.

An alternative viewpoint is advanced by Kant, that any action is moral not because of its utility or associated consequences, but because it is inherently right. 22,23 Specific to Kant's deontology, an act is moral if persons are treated with respect or as morally autonomous agents, in so doing we ought to "...treat human not as a means to an end but as an end in itself". ${ }^{23,24}$ Furthermore an act is moral if it can be wished to be a universal law or rule. ${ }^{25}$ It can be concluded, according to deontology, that extractions on consenting patients satisfy the principle of respect of persons or autonomy. It is debatable, whether dental extractions can be universalised for the relief of pain and sepsis, without exploring alternatives.

The mantra of Beauchamp and Childress espouses the belief that the ethical principles of autonomy, beneficence, non-maleficence and justice are critical to the evaluation of morality. Therefore a moral act should be voluntary and uncoerced, should be beneficial and not harm the individual. Furthermore the distribution of the act should be fair, equitable and non-discriminatory. Dental extractions are in all likelihood autonomously requested by patients without undue coercion from clinicians. This dental procedure provides relief of pain and sepsis and result in patient's "happiness". Indigent patients have the worst oral health status, are most likely to miss dental appointments and thus are unlikely to benefit from preventative dental services. ${ }^{26}$ Consequently, the treatment of choice for these patients remains emergency dental treatment including dental extractions. ${ }^{27}$ Therefore, dental extractions and related complications are disproportionally distributed by socio-economic status and impact the poor negatively.

\section{DISCUSSION}

Are dental extractions performed in the public oral health service, moral? According to Daniels we ask if dental extractions improve opportunities for the individual to achieve dreams and goals? In terms of Kant, we ask whether patients receiving this treatment are used as means to an end or as an end in themselves? Bentham and Mill would question whether dental extractions provide the greatest benefit for the greatest number of individuals? Similarly, Beauchamp and Childress evaluate the benefit to harm ratio of dental extractions as an indicator of moral status.

Dental extractions eventually lead to toothlessness, which is arguably detrimental to the normal functioning of affected patients. Edentulism is associated with limitations in speech, mastication and nutritional choices, which restricts the choices and opportunities possible for dentate individuals. ${ }^{9}$ Toothlessness negatively affects appearance and aesthetic concerns, self-perception and overall quality of life..$^{7-9}$ Hence the failure to manage dental diseases and the subsequent provision of "exclusive" dental extractions can have a debilitating effect on oral health related quality of life.

The oral health system that focusses exclusively on dental extraction is, according to Daniels, failing to maintain and protect those oral health opportunities which may be accumulated by preserving a full dentition. Consequently, such a system is also limiting the ability of the individual to "participate in the economic, social and political life of the society". By opportunities, Daniels refers to maximization of range of career prospects, social accomplishments, and productivity options, typical of a species. ${ }^{19}$ For example premature loss of anterior teeth normally affects aesthetics, which gravely compromises social equity among the young and socially engaged groupings. Similarly, extractions of posterior teeth may change the facial profile, and impact negatively on the masticatory function, choice of diet and nutritional status especially among the frail and old. ${ }^{9}$ According to Daniels such health states limit the range of "species specific" life plans and associated opportunities that affected individuals would like to construct for themselves.

Daniels' argument is premised on the proposition that dental extractions are unjust to the extent that they compromise the attainment and maintenance or protection of normal functioning of individuals within the realm of the species. Patients who have lost a significant number of teeth, are unable to consume a variety of foods, which further compromise their nutrition. Speech, aesthetics and social interaction can be gravely impacted. Viewed within the social context in which these individuals exist, the effects, while different, would compromise quality of life, life plans and overall happiness. Edentulous patients are unable to attain their plans and dreams, as they find it difficult to take all the opportunities open to them.

Pursuing further the mantra of Beauchamp and Childress's mantra, dental extractions may satisfy the principle of beneficence, as treated patients do not suffer further pain or "harm". ${ }^{28,29}$ However, unplanned and symptomatic serial tooth extractions lead to toothlessness, a form of dental disability and a serious handicap. The resultant effects of toothlessness produce harm beyond only clinical outcomes, including, social and psychological effects. Proportionally high extraction rates are contrary to the principle of nonmaleficence, ${ }^{28}$ as other forms of harm occur as a result. Health managers can argue that dental extractions are the most affordable and accessible alternative care, which provide relief from pain and sepsis. Overall the cost benefit or harm benefit of multiple extractions is high, to provide some justification to continue the practice.

Unfortunately, this treatment is largely reserved for the poor, uninsured, rural and largely African patients in the country. Dental extractions within the South African context are therefore unjust and discriminatory according to socio-economic and other factors. By design or necessity, this form of treatment would remain the only 
option for this population group unless drastic measures are implemented to change the system.

Evidence indicates that a plethora of treatment options are available for dental professionals to manage emergency dental problems, before resorting to dental extractions. Therefore, dental extractions cannot be made a universal treatment for the relief of pain and sepsis. Instead public oral health services must provide treatments alternative to dental extractions.

According to Kant, our social systems do not provide moral agency, hence informed patients cannot choose the treatment they deserve due to limited or no options. The public oral health system therefore does thwart the ability of moral beings to be an end in themselves.

In conclusion, Beauchamp and Childress, Bentham and Mills, Daniels and Kant provide compelling argument that while dental extractions result in immediate relief of pain and sepsis, they present with long term complications. Furthermore, extractions are discriminatory and unfair as they are unevenly offered and accepted by sections of the society. Lastly, extractions do not enable the individual to achieve life goals and dreams or exercise the autonomous choice of treatment they deserve. Therefore the high rates of dental extractions in the public oral health services are unjust, harmful, not wholly beneficial, and thus are not moral.

\section{IMPLICATIONS FOR DENTAL PRACTICE}

Notwithstanding the structural limitations and financial challenges facing the public oral health services, the spate of dental extractions remains morally unacceptable. Health professionals working in these areas are therefore morally obligated to be creative about averting this impending epidemic. As part of health promotion initiatives, oral health professionals should advocate for a change in the financing of oral health services and should focus on preventative initiatives to reduce the burden of caries and periodontal disease. Probably and most importantly, is for the oral health professionals to change their mindset about dental extractions. We ought to reject indiscriminate extractions and advocate for retention of permanent teeth for life. It is incumbent on oral health professionals to engage with patients in order to change their mindset about dental treatment and dental extractions in particular.

\section{References}

1. Lesolang R,MotlobaD,Lalloo R. Patterns and reasons for tooth extraction at the Winterveldt Clinic: 1998-2002:Scientific. South African Dental Journal 2009;64(5):214-8.

2. Anand PS,Kuriakose S. Causes and patterns of loss of permanent teeth among patients attending a dental teaching institution in south India.J Contemp Dent Pract. [Internet] 2009;10(5):58-68.

3. Ataguba JE-O,Alaba O. Explaining health inequalities in South Africa: a political economy perspective.Development Southern Africa 2012;29(5):756-64.

4. Benatar $\mathrm{S}$. The challenges of health disparities in South Africa. South African Medical Journal 2013;103(3):154-5.

5. Mayosi BM,Lawn JE,Van Niekerk A, et al. Health in South Africa: changes and challenges since 2009.The Lancet 2012;380(9858):2029-43.

6. Adeyemo WL,Taiwo OA,Oderinu $\mathrm{OH}$, et al. Oral health-related quality of life following non-surgical (routine) tooth extraction: a pilot study.Contemporary Clinical Dentistry 2012;3(4):427.

7. Ribeiro CG,Cascaes AM,Silva AER, et al. Edentulism, severe tooth toss and lack of functional dentition in elders: A study in Southern Brazil.Brazilian Dental Journal 2016;27(3):345-52.

8. Rodrigues SM,Oliveira AC,Vargas AMD,Moreira AN. Implications of edentulism on quality of life among elderly. International Journal of Environmental Research and Public Health 2012;9(1):100-9.

9. Emami E,de Souza RF,Kabawat M,Feine JS. The impact of edentulism on oral and general health.International Journal of Dentistry 2013;2013 : 498305

10. Hewlett SA,Yawson AE,Calys-Tagoe BN, et al. Edentulism and quality of life among older Ghanaian adults.BMC Oral Health 2015;15(1):48.

11. Benn SI. Egalitarianism and the Equal Consideration of Interests. Oxford University Press, 1997.

12. Alejandro R. The Limits of Rawlsian Justice. Baltimore, Johns Hopkins Press, 1998.

13. Singer BA. An extension of Rawls' theory of justice to environmental ethics. Environmental Ethics 1988;10(3): 217-31.

14. Rawls J. Justice as fairness.The Philosophical Review 1958:164-94.

15. Nagel T. Justice and nature.Oxford J. Legal Stud. 1997;17:303-32.

16. Vallentyne P. Brute luck, option luck, and equality of initial opportunities. Ethics 2002;112(3):529-57.

17. Daniels N. In Search of Equity. Springer, 1983: 1-41.

18. Daniels N. Normal functioning and the treatmentenhancement distinction.Cambridge Quarterly of Healthcare Ethics 2000;9(03):309-22.

19. Daniels N. Capabilities, opportunity, and health in: Measuring Justice: Primary Goods and Capabilities 2010:131-49.

20. Darwall SL. Consequentialism. Blakewell, 2003.

21. Peterson M. From consequentialism to utilitarianism.The Journal of Philosophy 2003;100(8):403-15.

22. Alexander L,Moore M. Deontological Ethics Stanford, 2007.

23. Hill TE. The Kantian Conception of Autonomy. Oxford University Press, 91-105, 1989.

24. Nagel T. Autonomy and Deontology. Oxford University Press, 1988.

25. Korsgaard C. Kant's formula of universal law.Pacific Philosophical Quarterly 1985;66(1-2).

26. Thomson W,Williams S,Broadbent J,Poulton R,Locker D. Long-term dental visiting patterns and adult oral health. Journal of Dental Research 2010;89(3):307-11.

27. Donaldson A, Everitt B,Newton T, et al. The effects of socia class and dental attendance on oral health. Journal of Dental Research 2008;87(1):60-4.

28. Beauchamp TL. The 'Four Principles' approach to health care ethics.Principles of Health Care Ethics 2007:3-10.

29. Beauchamp TL,Childress JF. Beneficence.Principles of Biomedical Ethics 2001;5:165-224. 